\title{
THE PRACTICAL IMPLEMENTATION OF AN EFFECTIVE DIGITAL READING PROGRAM TO ENHANCE LITERACY SKILLS WITH RESPECT TO SECOND-LANGUAGE LEARNERS DURING COVID- 19 PANDEMIC.
}

\author{
${ }^{1}$ D. HETHESIA, Dr. S. MERCY GNANA GANDHI ${ }^{2}$ \\ ${ }^{1}$ Research Scholar, Sathyabama Institute of Science and Technology \\ ${ }^{1}$ Assistant Professor, Panimalar Institute of Technology \\ ${ }^{2}$ Professor, Sathyabama Institute of Science and Technology
}

\begin{abstract}
The age of digitalization empowers the whole world with distinct digital tools and techniques which paves way for the paradigm shift in the process of teaching as well as learning. As it has been broadened, the paper assignment has been transferred into digital and conventional becomes contextual. In order to reflect such changes in the system of education, a study was taken up to report using ICT digital tool 'readworks.org' for digital assessment on the account of observing the impact of reading skills and encourage them to be imbibed on the level of comprehension. The blended learning is encouraged in college grades as students centered learning is being totally indulged in both off line and online class mode. This acknowledged change in the context of education motivates language instructors to show learners on examining information by comprehending the context and responding towards it. This work shows an experimental study which was done by 110 second language learners from two different branches of engineering college. The study consists of fiftyfour students from the department of Electrical and communication Engineering and fifty-six from the department EEE. During this pandemic this reading based activity provided
\end{abstract}

effective results and invigorates both language instructor and learners to be viably participated on this successful usage of the digital tool readworks.org in the fast and compelling enhancement of comprehension skills.

KEYWORDS: Language learners, ICT tools, Implementation, Comprehension Skills, Reading.

\section{INTRODUCTION:}

The impact of globalization is commonly seen all over the world including the system of education. In such digitalized world, language teachers have started adopting gradual changes from conventional to modern methodology of teaching reading comprehension skills to second language learners utilizing ICT tools and techniques in the classroom. When Covid-19 has achieved education institutions shut the entire route across the world tended the mode of education to be switched over online completely. In this way, educating second language learners has changed radically, with the indisputable climb of elearning, as the instruction mode is incorporated distantly digitalized. General suggestions from the language educators show that online learning helps at major cost in maintaining information with less 
time consume. Consequently, the Digital Age has wholly disturbed the world and the excitement for language learners happens even external the enlightening condition. It is highly responsible for any language teachers to comprehend the manner in which teens are effectively band together with the world in technology while enlightening the significance of reading comprehension skills.

The troubles become additionally perceiving and executing system to consolidate new reading practices to the classroom as 21 st century learners who have recently been swallowed in both pertinent and standard kind of learning. Furthermore, this paper refines on the work of student's abilities; describing and perceiving among ESL on how they are viably looking into using innovative resources and Web-based applications for reading skills. Additionally, the reading program called readworks.org gives good experience in comprehending the given passages correlated with traditional method of reading insight. From the outset, research was expressly focused on the aftereffect of conventional acts of reading before lock down. Afterward, the impact of readworks.org on enhancing comprehension skills was at the degree of striking execution.

\section{Literature Review}

As the global technology wholly imbibes the educational system, students are being restricted from the traditional mode of learning nowadays. In such kind of situation, students learning process has been altered with contextual method with increasing number of users (Mercy Gnana Gandhi 2020). Such alteration of teaching methodology based on technology gives way for studentcentered rather than teacher - centered (Hethesia D, 2020). Thus, Mercy Gnana Gandhi (2017) emphasised on the significance of technology in today's context in the process of learning in which both learners and teachers indulge. Therefore, changes in teaching methodology are inevitable. In this process of learning electronic assets such as mobile phones and laptops become very common (Basilaia, 2020). In a particularly sort of situation skills in reading have become furthermore combating part among the advanced students as per Shanahan (2008). To help the demonstration of reading skills, technology based teaching methodology offers the chance for learners as well as for educators to create cooperative learning (Mercy Gnana Gandhi, 2017).

In spite of the fact that this reading program ReadWorks can be utilized in a conventional classroom setting as a print hotspot for writings and materials, it is likewise an extremely amazing digital learning platform. Teachers can use the reading material with question sets, eBooks, and guide them with improving vocabulary. It is likewise free for the both instructors and students. Thus Benjamin Cebulash PD specialist says "ReadWorks, bridges the gap between research and practice in reading comprehension instruction. They use cognitive-science research to create engaging and impactful instructional materials and tools that are designed for immediate use within the practical realities of current U.S. classrooms". Many language instructors using this platform of reading recommends this has interesting passages for comprehension induces higher level thinking skills.

\section{Readworks.org}

ReadWorks is an online platform for the skills of reading with various exercise plans for learners of all levels. This digital tool was established with the objective of improving reading comprehension skills by acquiring the most recent education training examination into the classroom. Teachers can undoubtedly make a record and quickly start to look through ReadWorks' platform. This digital reading platform incorporates different sorts of passages. Contents given in this activity are sortable by catchphrases, grade or lexile levels, or by the particular ability or procedure that an instructor might want her learners to address. All 
sections are joined by related sets of question. ReadWorks additionally offers exercise plans adjusted to Common Core guidelines. Every exercise is joined by worksheets, realistic coordinators and different materials to encourage students learning. ReadWorks puts together its exercises into groups that can be shown consecutively over a progression of evaluation levels. Educators can keep an online "cover" brimming with the materials they have utilized, and furthermore give remarks on individual materials. All materials are printable. This is an unprecedented advanced tool for blended and collaborative learning. This device is refined considering the way that system, peer learning, and assessment get together inside content, decisively when students need help and motivation. The establishment makes it basic for instructive regions to share progressed instructive program, examine "the why" behind learner's execution, and access capable improvement with a speedy impact.

\section{Background}

Making an educational plan with the innovation makes more apparent in language learning cycle and it builds the student involvement and created powerful and simple learning. The fundamental idea behind the task is to examine the response after the classroom practice on reading which had been done as both printed and digitalized who was in control group and experimented group. For study first year students from engineering college from Tamilnadu were chosen. The sample study included 54 from ECE and 56 from EEE as group A and group B. During the course of examination, these two groups were given the reading activity articles in the printed structure and a while later with digitalized structure using the platform readworks.org. The answers were marked for the scores for fifty. In such an establishment it transforms into an exceptional test to the instructor to organized tasks that can challenge and all the while it was interesting for the students all through the semester.

\section{Scope}

The most appealing highlights about readworks.org is that any exercise can be doled out carefully, printed out, or projected before the class for free with resources. It implies any educator hoping to build comprehension skills of learners by offering support with multifaceted nature will probably discover something valuable. Utilizing the Article-a-Day expands learners experience on reading and improves vocabulary as well. Educators can assign articles that incorporate the audio, so that the learners can tune in listening while reading passages. This might be especially useful in supporting ESLs and battling readers. At long last, evaluate learners and give remarks by relegating sets of different result and short-answer questions are appreciated. Altogether the methods of reading in readworks.org upgrades accessible practice in comprehension skills.

\section{Research methodology}

This paper illuminates the use of the readworks.org which is totally significant on the abilities of reading comprehension of students from engineering college. An assessment was done to demonstrate with first year students and the outcomes were recorded for both traditional and modern method of tests by scores. Initially the learners were presented with traditional method. After that students were introduced to readworks.org which made them to be utilized in the following period of assessment. Additionally, with scores recorded, the survey from the students was additionally considered after their utilization with this reading platform readworks.org.

\section{Procedure}

\section{Reading test -Printed text based}

In the first course of this assessment, the reading activity was given based on the traditional 
classroom setting in the form of five reading passages for control group A and B as it was interceded with reading test by giving in printed content construction. After the study with conventional method, learner's average scores were considered. The passages were carefully chosen for reading activity in order to have interest among peer group.

Table: 1 Students' Reading Test Scores (Control Group)

\begin{tabular}{|c|c|c|}
\hline \multicolumn{2}{|l|}{ Students' Reading Test Scores (Control Group) } \\
\hline Control Group & $\begin{array}{c}\text { Average mark } \\
\text { (out of 50) }\end{array}$ & In Percentage \\
\hline A (ECE) & 26.27 & 52.54 \\
\hline B (EEE) & 25.73 & 51.46 \\
\hline
\end{tabular}

\section{Reading test - Readworks.org}

Rightly after conventional method of testing reading scores, both group $\mathrm{A}$ and $\mathrm{B}$ were introduced to this reading program readworks.org in third week of the study. At this time of examination after getting used with paper based, different articles were given for online reading activity with discussion in the digital platform among peer group. Learners were needed to finish a test for each assigned article in the readworkg.org; in any case this was not for a course grade yet rather to test the level of cognizance among students during the following period of the course. 


\section{Comprehension Questions}

Submitted January 26, 2021 at 07:40 PM

Multiple Choice: $7 / 7$ (100\%)

Written Response: 2.5/3 (83\%)

Total: 9.5/10 (95\%)
Teacher Feedback

Good in comprehending the given passages. still focused approach is needed

\section{What are two examples of technology that send information over long distances?}

\section{A. the human eye and computers \\ B. government officials and computers}

Table: 2 Students' Reading Test Scores (Experimental Group)

\begin{tabular}{|c|c|c|}
\hline \multicolumn{3}{|c|}{ Students' Reading Test Scores (Experimental Group) } \\
\hline Experimental Group & $\begin{array}{c}\text { Average mark } \\
\text { (out of 50) }\end{array}$ & In Percentage \\
\hline A (ECE) & 28.81 & 57.62 \\
\hline B (EEE) & 27.48 & 54.96 \\
\hline
\end{tabular}




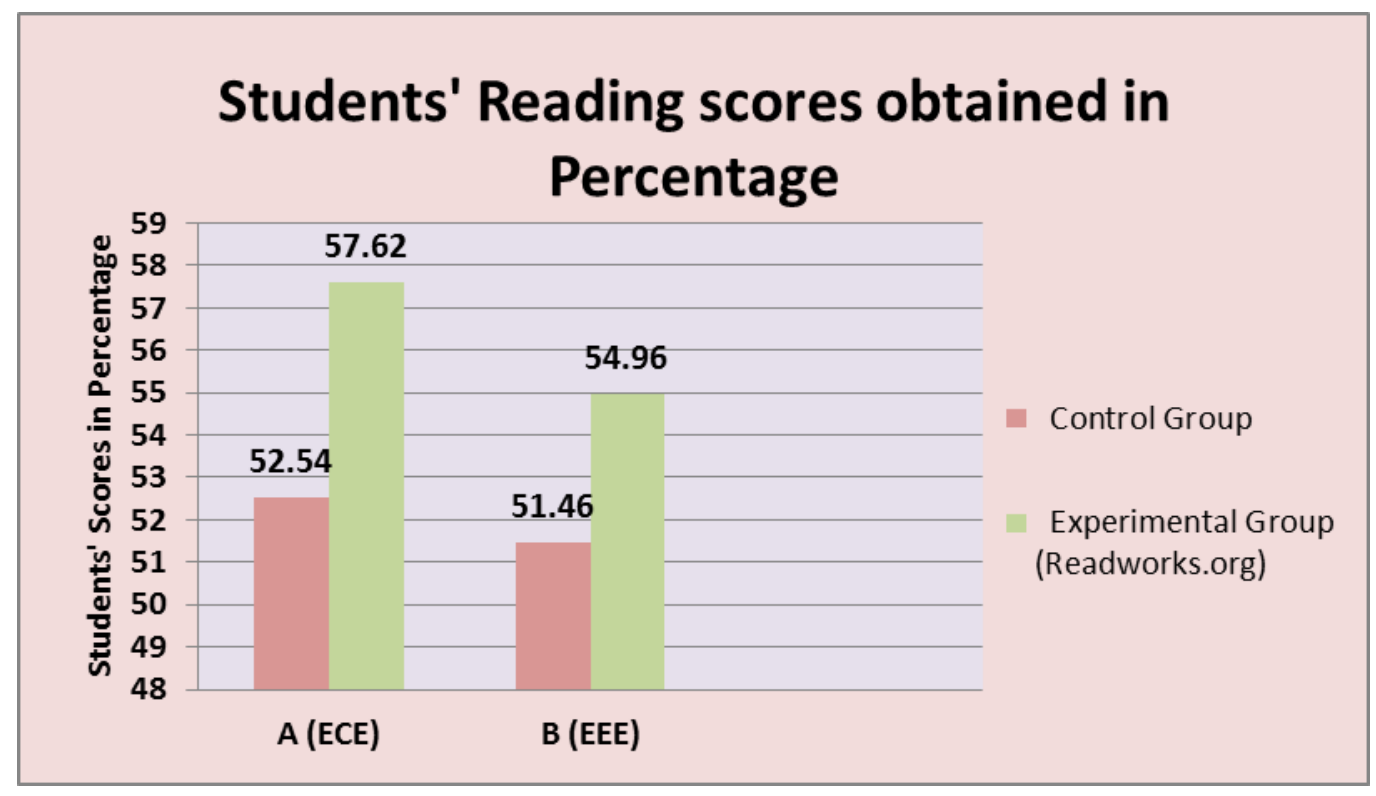

Fig 1: Marks obtained by the students (ECE \& EEE)

Figure 1 shows the scores acquired by every student in group A and B. An impressive degree of augmentation can be seen in Readworks.org contrasting with Text based tests. A few students' have a high level of increment, while others have low. Students who scored low marks were not almost locked in. It might be seen that by far most of the learners have exhibited increase in a way that is better than anticipated. This is because the vast majority of students were enthusiastic about giving responses over the online based and easy to read everything being equal out of the traditional classroom.

In order to observe the outcome of a learner after using this reading platform Readworks.org, a survey was done to the participants. This survey contains ten statements.

1. Readworks.org arouses me to turn out to be better reader

2. The development of my vocabulary expanded with the help of Readworks.org
3. Readworks.org turns into a kind of learners focused

4. This instrument is preferred rules over the conventional course reading

5. I favour Readworks.org as it has many fascinating articles with continuous occasions

6. The self-sufficient learning is advanced utilizing this tool.

7. I discover improvement in my reading ability utilizing Readworks.org

8. Readworks.org is exceedingly integral asset in knowing current information

9. I read Readworks.org articles which was not doled out of making thinking skills

10. I feel sure and synergistic utilizing this device of reading.

After the study the students were asked to give their feedback based on reading task utilizing Readworks.org.

Table: 3 Questionnaire Results from students' feedback 


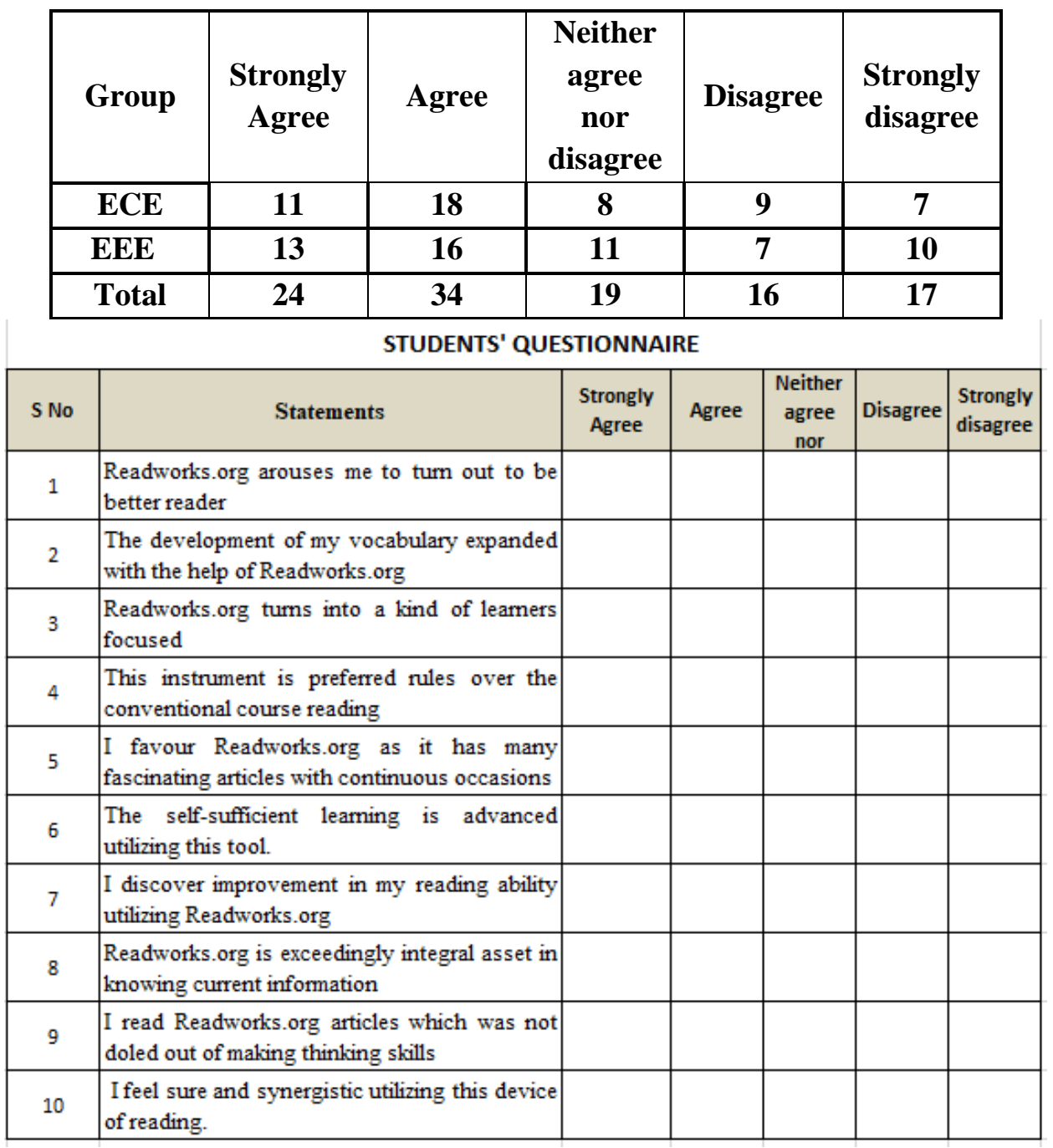

\section{Students' Feedback (In Percentage)}

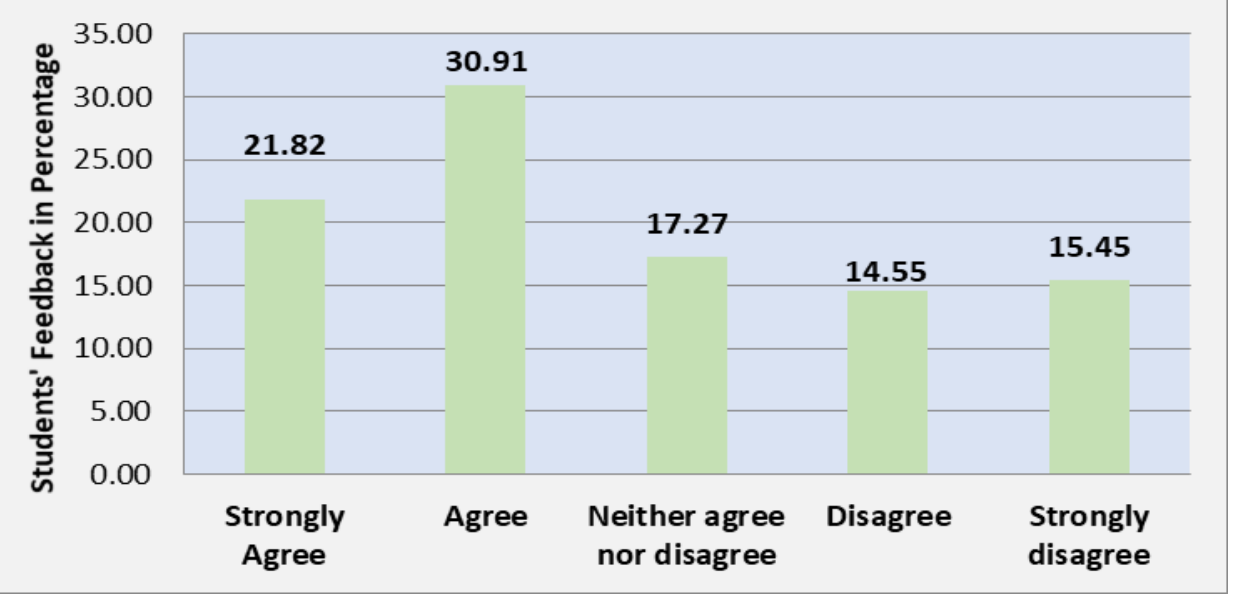

Fig: 2 Questionnaire results in Percentage (Consolidated) 
As students were given articles for the classroom activity, they were drawn closer to get back with the response as demonstrated. Fig 2 addresses the reactions given by the learners from both groups $\mathrm{A}$ and B. $21.82 \%$ of the learners emphatically concur on the utilization of Readworks.org platform for enhancing reading comprehension skills. $30.91 \%$ was given to the individuals who were totally agreed with this usage of readworks.org to improve reading habit as well. $17.27 \%$ was given to the individuals who are in impartial condition. $14.55 \%$ was offered by the students who disagree with this way of learning reading skills. Finally, $15.45 \%$ of the students group were immovably couldn't resist repudiating Readworks.org proposals for the classroom.

\section{Data collection}

The information which was used in this examination was students' overview. The reason behind the study is to value their affirmations regarding the thought of Readworks.org articles and their reactions. The solicitations were made by the recommendations given by the students. They had decided to complete the task assigned with the test based.

\section{Data Analysis}

Various exercises were done to collect the information with various assessments based on the responses from students while responding to comprehension questions and the survey. Initially, a large portion of observed notes were inspected. After that student comprehension skills based questions and responses in the digital platform readworks.org were observed. Followed by the examination on student's conventional method and contextual method of comprehending passages were recorded. Finally, responses were taken into account as survey questions were distributed among the experimented students

The difficulties of using the platform digitally are the best approach to realize apparatuses feasibly, perceiving how it works, and how to join those digital devices in learning. Finally, using digital tools in the language classroom make learners careful with the changing of communication nowadays. With the help of digital tools, students not simply sort various ways to access about the material and acquiring information, yet they can regard and become astute while using digital platform for learning.

\section{Findings and Discussion}

In this manner after careful examination and evaluation of the gathered data barely any subjects have created. These subjects were discovered dependably all through the data and show the benefits of Readworks.org in the reading practice. Learner's motivation embraces development in reading comprehension skills with authentic learning practice. Scarcely any bugs have been capable from time to time; at this point by and large the convenience is marvellous. Poor readers using on this digital tool exhibited an extreme energy in the examination. As a teacher, Readworks.org can be guaranteed for the learners which are basically reassuring in reading and updates their preference levels in each insightful setting.

\section{Conclusion:}

As huge changes made in the system of education, there was heaps of impediment in indicating team towards acclimating to development pre-COVID 19 crises and in light of the situation most of the educational environment all over the world has changed advancement and started taking virtual classes and their experience are unimaginable. In the wake of getting the headway of the students on utilizing Readworks.org, the level of reading has become an appealing event close by the sufficiency. Exactly when learners were drawn closer to reading and attempting test on four to five articles in about fourteen days empowered their 
motivation with capacity. Displaying such incredible shows that all of these stuffs of Readworks.org are essential pieces of effectively executing Readworks.org in the language classroom and they each moreover accept a task in supporting for the development of students' reading comprehension. The central issue being

\section{References}

[1] Basilaia, G., \& Kvavadze, D. (2020). Transition to Online Education in Schools during a SARSCoV-2 Coronavirus (COVID-19) Pandemic in Georgia. Pedagogical Research, 5(4), em0060. https://doi.org/10.29333/pr/7937.

[2] Byrne, Richard. (2015). Readworks.org Create, Distribute, Assess Reading Activities: Free Technology for Teachers.

[3] Gnana Gandhi, Mercy, S. (2020). Modelling Analysis with Advanced Technology in English Online Learning Platform. JCR. 2020; 7(12): 10601064. doi:10.31838/jcr.07.12.186

[4] Gnana Gandhi, Mercy, S. (2017) A study on Integrating Technology in Material Development and Task Design. International Journal of Humanities and Social Science Invention. Vol 6 Issue - 10, PP.46-49

[5] Gnana Gandhi, Mercy, S, "A study on Integrating Technology in Material Development and Task Design", 2017.

[6] Hethesia, D. (2020). Blogging - An Efficient Tool to Incorporate Technology and Reading Skills, International Journal of Scientific \& Technology Research (IJSTR) Volume 9, Issue 1. Jan. (2020).

[7] Shanahan, T., \& Shanahan, C. (2008). Teaching disciplinary literacy to adolescents: Rethinking content area literacy. Harvard Educational Review, 78(1), 40-59. that there is reliably affluence where learners can habitually discover something spellbinding to read. Thus it could be utilized as a focus point for the establishment of reading skills while constructed with effective learning with scholastics.

[8] Warner, W., \& Jones, J. (2011). The wonder of words: Using technology to support vocabulary instruction. Agricultural Education Magazine, 83(6), 7-9.

[9] Wilson, Katie Ann (2014). App / Tool of the Week - Readworks.org. Diary of a Techie Chick

[10] https://www.teq.com/news/readwo rks-distance-learning-platform-readingcomprehension/ 